higher mRSS $(p=0.001)$ ] and vasculopathic manifestations [late scleroderma pattern $(p=0.002)$ and digital ulcers $(p=0.006)]$ of the disease (Figure 1$)$.

Conclusions: in clinical practice, different age-related or non-related RRI cut-offs must be used when looking for renal or extrarenal SSc-induced damages.

References:

[1] Boddi, Intern Emerg Med 2015;2)Boddi, Am J Hypertens 1996;3)Ponte, Hypertension 2014;4)Platt, Am J Roentgenol 1989;5)Rivolta,Arthritis Rheum 1996;6)Rosato, Seminar ARthritis Rheum 2012;7)Rosato, Arthritis Care Res 2014.

Disclosure of Interest: None declared

DOI: 10.1136/annrheumdis-2017-eular.6420

\section{AB0623 PROGNOSTIC VALUE OF RENAL RESISTIVE INDEX (RRI) IN SYSTEMIC SCLEROSIS: PRELIMINARY DATA FROM A SINGLE CENTRE}

C. Bruni ${ }^{1}$, V. Maestripieri ${ }^{2}$, G. Tesei ${ }^{1}$, M. Chiostri ${ }^{3}$, C. Sambalino ${ }^{3}$,

S. Guiducci ${ }^{1}$, S. Bellando-Randone ${ }^{1}$, M. Boddi ${ }^{3}$, M. Matucci-Cerinic ${ }^{1}$.

${ }^{1}$ Department of Experimental and Clinical Medicine, Division of Rheumatology:

${ }^{2}$ Department of Internal Medicine, Division of Medicine for Care Complexity III,

University of Florence; ${ }^{3}$ Department of Heart and Vessels, Division of Cardiology

I, Azienda Ospedaliera Universitaria Careggi, Firenze, Italy

Background: Renal Resistive Index (RRI- measured with Renal arteries Doppler ultrasound) is a useful technique to evaluate vascular and tubular-interstitial damage in both general and systemic sclerosis (SSc) population, where increased RRI values correlates with longer disease duration [1], lower glomerular filtration rate and more advanced nailfold-videocapillaroscopy pattern [2]. Moreover, higher RRI values were seen in SSc patients with new occurrence of digital ulcers [3].

Objectives: to test the prognostic value of RRI [absolute, $\geq 0.70$ and SSc ageadjusted pathologic value (Table1)] and RRI delta change in predicting general and organ-specific worsening in scleroderma patients.

Methods: SSc patients classified according to ACR/EULAR 2013 criteria were enrolled. Demographics data and renal ultrasound data were collected. Data on clinical worsening had been collected as herewith specified: a) Skin worsening as an increase of $m R S S \geq 5$ units, b) Peripheral vascular worsening as the appearance of new digital ulcers or the worsening of nailfold videocapillaroscopy scleroderma pattern, c) Lung worsening as decline of $\mathrm{FVC}>15 \%$ or $\mathrm{FVC}<80 \%$ with new detection of ILD on chest HRCT or worsening of HRCT-ILD extent, d) Cardiac worsening as new onset of left ventricular failure requiring treatments or new onset of $\mathrm{PAH}$ confirmed on $\mathrm{RHC}$ or detection of severe ventricular arrhythmias on 24h EKG, e) Renal worsening as a new scleroderma renal crisis or reduction of creatinine clearance $\leq 30 \mathrm{ml} / \mathrm{min}$. General worsening was recorded in case of death due to SSc or for any of the above organ-specific worsening. Data were analysed as appropriate with SPSS vers. 20.0.

Results: 190 SSc patients (age $56.3 \pm 15.0$ yrs, 170 women, disease duration $6 \pm 8$ yrs, 65 with a follow up RRI measurement after $2.8 \pm 0.9$ years) were enrolled. After a mean clinical follow-up of $3.6 \pm 2.6$ years, $89(46.8 \%)$ pts showed general worsening. Skin, peripheral vascular, cardiac, lung and renal worsening were detected in $14(7.4 \%), 40(21 \%), 32(16.8 \%), 38(20 \%)$ and $11(5.8 \%)$ patients respectively. We registered $10(5.2 \%)$ deaths and $43(22.6 \%)$ patients with multiple organ worsening. Both absolute value of RRI and $\geq 0.70$ RRI cut-off showed no significant association with organ or global clinical worsening, At the opposite, RRI cut-offs adjusted for age were associated with cardiac worsening ( $p=0.065$ $=-$ Figure 1). When in 65 patients the pattern of delta RRI and clinical worsening were analysed (Table 1), wider RRI changes were associated with general worsening $(p=0.029)$ and cardiac worsening $(p=0.006)$. The significance of these associations increased when sub-analyse was repeated focused on patients with normal SSc age-adjusted RRI values at baseline evaluation ( $p=0.017$ and $p<0.001$ respectively, Figure 1 ).

\begin{tabular}{lc}
\hline Age & Proposed SSc age-adjusted pathologic cutoff \\
\hline 1st quartile, $\leq 48$ years & $\geq 0,68$ \\
2nd quartile, 49-58 years & $\geq 0,69$ \\
3rd quartile, 59-67 years & $\geq 0,75$ \\
4th quartile, $\geq 68$ years & $\geq 0,77$ \\
\hline
\end{tabular}

\begin{tabular}{|c|c|c|c|c|c|c|c|c|c|c|}
\hline & \multicolumn{2}{|c|}{$\begin{array}{c}\text { RRI basal } \\
\text { value } \\
\text { (190 pts) }\end{array}$} & \multicolumn{2}{|c|}{$\begin{array}{l}\text { RRI>0,70 } \\
\text { (85 pts) }\end{array}$} & \multicolumn{2}{|c|}{$\begin{array}{l}\text { SSc age- } \\
\text { adjusted } \\
\text { pathologic } \\
\text { (61 pts) }\end{array}$} & \multicolumn{2}{|c|}{$\begin{array}{l}\Delta R R 1 \\
\text { (available } 65 \text { pts) }\end{array}$} & \multicolumn{2}{|c|}{$\begin{array}{l}\Delta R R I \text { in baseline SSc age- } \\
\text { adjusted normal RRI } \\
\text { (45 patients) }\end{array}$} \\
\hline & $n(\%)$ & $\begin{array}{c}\mathrm{p} \\
\text { value }\end{array}$ & $n(\%)$ & $\begin{array}{c}\mathrm{p} \\
\text { value }\end{array}$ & $n(\%)$ & $p$ value & (n) meantSD & $p$ value & (n) mean $\pm S D$ & $\mathrm{p}$ value \\
\hline $\begin{array}{c}\text { General } \\
\text { Worsening }\end{array}$ & \begin{tabular}{|c}
89 \\
$(46,8)$
\end{tabular} & N.S. & $\begin{array}{c}37 \\
(43,5)\end{array}$ & N.S. & $\begin{array}{c}31 \\
(50,8)\end{array}$ & N.S. & $\begin{array}{l}(33)+0,03 \pm 0,05 \\
\text { vs } \\
\text { (42) } 0,00 \pm 0,04\end{array}$ & 0,029 & $\begin{array}{c}(24)+0,04 \pm 0,04 \\
\text { vs } \\
(21)+0,01 \pm 0,03\end{array}$ & 0,017 \\
\hline $\begin{array}{c}\text { Cardiac } \\
\text { Worsening }\end{array}$ & $\begin{array}{c}32 \\
(16,8)\end{array}$ & N.S. & $\begin{array}{c}16 \\
(18,8)\end{array}$ & N.S. & $\begin{array}{c}15 \\
(24,5)\end{array}$ & $p<0,001$ & $\begin{array}{c}(13)+0,05 \pm 0,05 \\
\text { vs } \\
(52)+0,01 \pm 0,04\end{array}$ & $\mathrm{p}=0,006$ & $\begin{array}{c}(7)+0,08 \pm 0,03 \\
\text { vs } \\
(38)+0,02 \pm 0,04\end{array}$ & $p<0,001$ \\
\hline
\end{tabular}

Conclusions: increase in RRI could be used as a sentinel sign for general and cardiac worsening in SSc patients, especially when age-related RRI variations are taken into account.

References:

[1] Rivolta R, Arthritis Rheum. 1996.

[2] Rosato E, Semin Arthritis Rheum. 2012.

[3] Rosato E, Arthritis Care Res (Hoboken). 2014.
Disclosure of Interest: None declared

DOI: 10.1136/annrheumdis-2017-eular.6533

\section{AB0624 INTERSTICTIAL LUNG DISEASE IN SCLERODERMA: SEVERITY ASSOCIATED FACTORS. OBJETIVES}

D. Sanchez Cano ${ }^{1}$, N. Ortego Centeno ${ }^{2}$, M.T. Cruces Moreno ${ }^{1}$, L. Sáez Comet $^{3}$, M. Freire ${ }^{4}$, J.A. Todlí Parra ${ }^{5}$, M. Rodríguez Caballeira ${ }^{6}$, C. Simeón Aznar ${ }^{7}$ on behalf of RESCLE. ${ }^{1}$ Internal Medicine; ${ }^{2}$ Sistemic Autoimmune Diseases Unit, Hospital Campus de la Salud, GRANADA; ${ }^{3}$ Internal Medicine, Hospital Universitario Miguel Servet, Zaragoza; ${ }^{4}$ Unidad Trombosis y Vasculitis, Hospital Xeral de Vigo, VIGO; ${ }^{5}$ Internal Medicine, Hospital Universitario la Fe, Valencia; ${ }^{6}$ Internal Medicine, Hospital Universitari Mútua de Terrassa, Terrassa; ${ }^{7}$ Sistemic Autoimmune Diseases Unit, H. Universitari General de la Vall D'hebron., Barcelona, Spain

Background: Systemic sclerosis (SSc) can virtually affect any organ system (such as lungs, kidneys, gastrointestinal tract, and heart). However, it is the pulmonary manifestations that account for the majority of deaths, especially interstitial lung disease (ILD) and pulmonary arterial hypertension (PAH).

Objectives: Our aim was to assess the differences between severe and mild-to-moderate ILD in SSc.

Methods: A descriptive study was performed, using the available data from the Spanish Scleroderma Study Group (RESCLE). ILD was deemed as serious when forced vital capacity (FVC) was $<50 \%$. Patients were classified attending the modified classification criteria proposed by LeRoy and Megdsger.

Results: Fourteen referral centers for SSc participated in the registry. By April 2014,1374 patients with SSc had been enrolled, 541 of whom (39.4\%) had ILD, which was severe in 72 of them (13.2\%). There were no significant differences as far as sex and age at onset is concerned. Patients with diffuse SSc presented with severe ILD more frequently than those with limited SSc $(57 \%$ vs. $35 \%, p=0.002)$, as well as those who had tested positive for ATA ( $51 \%$ vs. $33 \%, p=0.005)$. Aditionally, prevalence of $\mathrm{FVC}<50 \%$ was higher in patients with myopathy $32 \%$ vs. $15 \%, p=0.002$ ). Mean FVC was $40.2 \pm 6.4$ in the severe ILD group, whilst it was $80.3 \pm 18.9$ in the mild-to-moderate one $(p<0.001)$, and mean DLco was $36.7 \pm 15.2$ and $62.9 \pm 34.5$, respectively $(p<0.001)$. Likewise, DLco $<70 \%$ was also more frequent among patients with severe ILD $(100 \%$ vs. $69 \%, p<0.001)$, as well as mean $\mathrm{DLCO} / \mathrm{VA}(56.2 \pm 24.2$ vs. $74.2 \pm 42.0, \mathrm{p}=0.002)$. PAPs was equally higher when $\mathrm{FVC}<50 \%$ ( $42.2 \pm 18.2$ vs. $35.1 \pm 13.4, \mathrm{p}=0.034)$, and so was the frequency of PAPs $>40 \mathrm{mmHg}(66 \%$ vs. $29 \%, p<0.001)$ and PAH by right heart catheterism ( $19 \%$ vs. $11 \%, p=0.050$ ). Finally, by means of a multiple logistic regression, both ATA positivity [OR $0.17(0.05-0.58), p=0.005]$ and low DLco [0.93 (0.91-0.95), $p=0.000$ ] were found to be related with $\mathrm{FVC}<50 \%$

Conclusions: Patients with ACA positivity and with a limited variant of SSc seem to be at lower risk of severe interstitial lung involvement. Furthermore, the presence of myopathy may contribute to explain the decrease of FVC in SSc patients.

References:

[1] Steen VD, Medsger TA. Changes in causes of death in systemic sclerosis, 1972-2002. Ann Rheum Dis 2007; 66: 940-4.

[2] LeRoy EC, Medsger TA, Jr. Criteria for the classification of early systemic sclerosis. J Rheumatol 2001; 28: 1573-6.

Disclosure of Interest: None declared

DOI: 10.1136/annrheumdis-2017-eular.2545

\section{AB0625 AUTOANTIBODY PROFILE IN PATIENTS DIAGNOSED WITH IDIOPATHIC INFLAMMATORY MYOPATHY: MULTICENTER REGISTRY ON INFLAMMATORY MYOSITIS FROM THE RHEUMATOLOGY SOCIETY IN MADRID, SPAIN}

D.C. Hernández Flórez ${ }^{1}$, L. Valor ${ }^{1}$, J. Martinez ${ }^{1}$, B. Joven ${ }^{2}$, L. Nuno ${ }^{3}$, C. Larena ${ }^{4}$, I. Llorente ${ }^{5}$, C. Barbadillo ${ }^{6}$, P. Garcia de la Pena ${ }^{7}$, L. Ruiz ${ }^{8}$, H. Moruno ${ }^{9}$, T. Cobo $^{10}$, R. Almodovar ${ }^{11}$, L. Lojo ${ }^{12}$, M. Garcia ${ }^{13}$, F. Lopez-Longo ${ }^{1} .{ }^{1} \mathrm{H}$. Gregorio Maranon; ${ }^{2} \mathrm{H} .12$ de Octubre; ${ }^{3} \mathrm{H}$.La Paz; ${ }^{4}$ H.Ramon y cajal; ${ }^{5}$ H.La Princesa; ${ }^{6}$ H.Puerta de Hierro; ${ }^{7}$ H. Norte Sanchinarro; ${ }^{8}$ H.Nino Jesus; ${ }^{9}$ H.Principe de Asturias, Madrid; ${ }^{10}$ H.Infanta Sofia, Asturias; ${ }^{11}$ H. F.Alcorcon; ${ }^{12}$ H.Infanta Leonor; ${ }^{13}$ InMusc, Madrid, Spain

Background: Inflammatory myopathies (IIM) are a heterogeneous group of autoimmune rheumatic diseases characterized by muscle inflammation and progressive weakness. They include any kind of primary inflammatory muscle disease that is not otherwise better explained by metabolic, toxic, infectious, neurologic or inherited causes. The presence of autoantibodies (AA) in IIM is variable and they can recognize nuclear and cytoplasmic cellular components. Objectives: To evaluate the AA profile in patients diagnosed with IIM.

Methods: We evaluated 479 patients that included 12 hospitals belonging to the IIM registry of the Rheumatology Society in Madrid (SORCOM-REMICAM) with diagnosis from January 1980 to December 2014. All patients were diagnosed of IIM according to Bohan and Peter criteria. The AAs evaluated were ANA $(n=476)$, anti-Jo1 $(n=457)$, anti-RNP $(n=427)$, anti-MI2 $(n=159)$ and ACA $(n=293)$, according to the standard techniques in the respective laboratories. The presence of ANA was considered valid with at least two positive determinations. The AAs were compared according to the classification I) as dermatomyositis (primary 